\title{
Complications of Anterior and Posterior Cervical Spine Surgery
}

\author{
Jason Pui Yin Cheung, Keith Dip-Kei Luk \\ Department of Orthopaedics and Traumatology, The University of Hong Kong, Pokfulam, Hong Kong, SAR, China
}

Cervical spine surgery performed for the correct indications yields good results. However, surgeons need to be mindful of the many possible pitfalls. Complications may occur starting from the anaesthestic procedure and patient positioning to dura exposure and instrumentation. This review examines specific complications related to anterior and posterior cervical spine surgery, discusses their causes and considers methods to prevent or treat them. In general, avoiding complications is best achieved with meticulous preoperative analysis of the pathology, good patient selection for a specific procedure and careful execution of the surgery. Cervical spine surgery is usually effective in treating most pathologies and only a reasonable complication rate exists.

Keywords: Complications; Cervical; Spine; Surgery

\section{Introduction}

Cervical spine surgery includes many common surgical procedures performed by spine surgeons. The pathologies treated include radiculopathy, myelopathy, instability caused by degeneration or trauma, infection and tumors. Surgical strategies include decompression of neural elements and stabilization when necessary, either through an anterior, posterior or combined approach. The approach selection is influenced by the location of the compressive element, type of fracture or ligament injury and the overall alignment. Surgeons need to be aware of possible complications with each step of the procedure and the methods to avoid or manage them.

This literature review discusses general, access-related, decompression-related, procedure-related and fusionrelated complications in regard to both anterior and posterior surgery. Special emphasis is made on methods to avoid these complications.

\section{General Complications}

\section{Anaesthesia and positioning}

The reported incidence of postoperative respiratory compromise varies from $0 \%-14 \%$ [1-4]. This is likely caused by trauma to the anterior soft-tissue and prolonged prone position; both can result in upper airway oedema and impaired respiration $[1,3]$. During induction of general anaesthesia in patients with cervical instabilities, no protective mechanism exists for the compromised spinal cord due to the paralysed neck musculature. Forceful manipulation during laryngoscopy and tracheal intubation may jeopardise the spinal cord. Manual inline axial stabilisation with fibre-optic nasal or oral endoscopy can reduce risk of spinal cord injury during tracheal intubation.

\footnotetext{
Received May 26, 2015; Revised Jun 7, 2015; Accepted Jun 8, 2015

Corresponding author: Keith Dip-Kei Luk

Department of Orthopaedics and Traumatology, The University of Hong Kong, Queen Mary Hospital,

Pokfulam, Hong Kong SAR, China

Tel: +852-2255-4254, Fax: +852-2817-4392, E-mail: hrmoldk@hku.hk
} 
Controlled hypotension reduces blood loss and facilitates surgical exposure. Unwanted effects include spinal cord ischaemia and neurological damage. At least $65 \%$ of the usual spinal blood flow is required for physiological integrity and a $12 \%$ decrease in blood flow may produce paralysis [5,6]. A mean arterial pressure of $65 \mathrm{~mm} \mathrm{Hg}$ or $20 \mathrm{~mm} \mathrm{Hg}$ below baseline in normotensive patients is usually safe [7]. Maintaining adequate blood pressure is important for neural perfusion. This is more apparent in cases of traumatic spinal cord injury where the patient may already have a contused and swollen spinal cord. The first step in handling any intraoperative drop in spinal cord signal/function is increasing the blood pressure.

Positioning the patient is important to permit access to the surgical field and is necessary to avoid pressure areas or iatrogenic injuries. Adequate head and neck control is mandatory to prevent damage to the spinal cord, such as skeletal traction via Halo ring or Mayfield tongs. Being in a prone position may increase intraocular pressure leading to ischaemia, decreased perfusion pressure and blood supply to the retina. This can result in ischaemic optic neuropathy, blindness and occipital stroke. Pressure over the eyeballs due to Mayfield headrest or Gardner Wells tongs should be avoided. Arms are kept by the side and shoulders are usually pulled distally and taped to the operating table to facilitate lateral radiographs. Excessive traction with the tape or extension of shoulders below the coracoid process should be avoided to prevent compression of the brachial plexus. Hanging the arm over the edge of the operating table can injure the radial nerve. This should also be avoided. Injury to the common peroneal nerve can occur if the legs are placed in abduction and external rotation, which can cause pressure over the fibular head. Adequate padding under pressure points can prevent skin and peripheral nerve complications especially in prolonged prone positioning. Areas of concern include the face, iliac crests, lower ribs, patella and anterior ankle joints.

\section{Bone grafting}

Long-term harvest site pain ( 3 months to 2 years) reportedly occurs in $2.5 \%$ of iliac crest bone grafting cases [8]. This is more common with tricortical graft harvest. Nerve injuries are not uncommon. Ilioinguinal neuralgia can occur by compression from the retractor against the iliac crest. In posterior bone grafting, the superior cluneal nerves may be injured as they cross lateral to the posterior superior iliac spine. Sensory deficit to the superior twothirds of the buttocks may occur. Thus, an oblique incision is usually recommended. Postoperative donor site pain can be avoided by careful handling of soft tissues, minimal subperiosteal dissection or stripping of pelvic muscles and anterior thigh musculotendinous attachments to the iliac crest and protection of sensory cutaneous nerves. Superficial haematoma formation, seroma formation and infection are typically treated nonoperatively. Watertight closure of wounds is important to prevent seroma formation. Many clinicians associate deep wound haematoma formation with the development of deep infection and the use of the drain has been hypothesised to reduce morbidity. Yet, a prospective randomised study of 112 procedures showed no difference in developing wound complications (10\%) with the use of a suction drain [9].

Anterior harvest has risk of injury to the lateral femoral cutaneous or ilioinguinal nerves due to direct injury, retraction, fracture or subfascial haematoma. Incisional hernia is a rare complication $(0.5 \%)$ that occurs via ilium defects without adequate closure of the abdominal muscles [10]. To avoid herniation, dissection should be mainly limited to the pelvis outer table and extensive stripping of abdominal and pelvic muscle attachments should be avoided. Anterior iliac crest harvest should be more than $3 \mathrm{~cm}$ posterior to the anterior superior iliac spine $[8,11,12]$. Failure to observe these precautions may lead to avulsion fractures of the anterior superior iliac spine due to forceful contractions of the Sartorius and tensor fasciae latae. Avulsion injuries are more common with bicortical and tricortical anterior superior iliac spine grafts than taking cancellous bone between the cortical tables [11].

Superior gluteal artery injuries are common in posterior bone graft harvesting. Injury typically involves excessive retraction, extension of the dissection or dislodgement of the retractor or osteotome into the sciatic notch. After transection, the superior gluteal artery frequently retracts into the intrapelvic position behind the sacrosciatic notch and is difficult to approach posteriorly without removing bone from the notch. Direct ligation requires turning the patient supine to enable exploration through an anterior retroperitoneal approach. Ligation does not carry significant sequelae, such as muscle necrosis or ischemia, due to good collateral anastomosis. The recommended alternative approach is vessel embolization with the aid of an interventional radiologist. Prevention of injury requires careful assessment of the safety boundaries. The caudal 
limit of harvesting should be the inferior margin of the origin of the gluteus maximus at the area of the posterosuperior iliac spine. Retractor placement in the sciatic notch should be avoided and the osteotome should be directed cephalad and away from the sciatic notch.

Breaching of the sacroiliac joint may occur with posterior iliac harvesting that is too far posterior, which leads to fracture. With injury to the posterior sacroiliac ligaments, possible sequelae include sacroiliac joint instability, pain and arthrosis. Gait disturbance could also occur due to the stripping of the hip abductor muscle origins at the ilium leading to pain during the stance phase.

\section{Wound infection and discitis}

The incidence of postoperative wound infections in anterior cervical discectomy and fusion is $0.1 \%-1.6 \%$ [13]. Postoperative infection usually presents as pain, local erythema and wound drainage. Fever, chills, night sweats and respiratory compromise can also occur in more septic presentations. Infection involving the retropharynx in anterior procedures may present as painful swallowing, travel cephalad or caudal-related mediastinitis. Neurological complications can also develop due to pressure caused by an epidural abscess. Infectious organisms can also tract into the disc space and the adjacent vertebrae causing osteomyelitis. Long-term prognosis of discitis is generally good. After 2-years, up to $90 \%$ of patients are pain-free and $75 \%$ of patients develop stable fibrous union or spontaneous bony fusion [14].

The duration of surgery correlates with the bacterial load. More than $10^{5}$ organisms can be found in surgical wounds after 5.7 hours [15] and operations longer than 3 hours increase the risk of infection [16]. Good surgical technique is fundamental for reducing infection. This includes meticulous dissection within avascular planes, potential dead spaces, intermittent release of retractors, careful haemostasis with frequent irrigation and closure of potential dead spaces. Local application of vancomycin powder is also useful in reducing surgical site infections, especially in long posterior fusions [17].

Acute infections are usually caused by gram-positive cocci including Staphylococcus aureus, Staphylococcus epidermidis and beta-hemolytic streptococci $[16,18,19]$. Klebsiella, Escherichia coli, Pseudomonas, Aerobacter and Proteus are possible gram-negative species commonly present in intravenous drug users. Culprits for delayed or chronic infections are usually low virulence skin flora like Propionibacterium [20] and diphtheroids [19].

\section{Cervical traction}

Local complications of traction pins include tract infection, dura penetration leading to leakage of cerebrospinal fluid (CSF), brain abscess and meningitis, propagation of fractures in presence of skull fractures, loss of fixation, complications of hanging weights, arterial injuries, overdistraction and related disc protrusion, missed distraction type cervical injuries and pin malpositioning. Systemic complications that can arise due to prolonged bed rest include pneumonia, thromboembolism, sepsis and decubitius ulcers.

Intracranial pin penetration is rare and usually occurs subsequent to fall injuries, improper placement and overtightening of pins, prolonged use of halo devices and patient noncompliance. A review of 179 patients with halo insertion reported pin loosening as the most common complication (36\%), followed by pin-site infections (20\%), disfiguring scars (9\%), nerve injuries (2\%) and dural penetration (1\%) [21]. Complications in paediatric patients occur more often (up to $68 \%$ ) with most being pin-site infections [22]. In children with thin skulls, multiple (68) pins, special pin designs [23] and use of torque wrenches at lower insertion torques (4-6 in-lbs) [24] are recommended to prevent penetration [25].

Pin loosening may lead to loss of fracture reduction or spinal malalignment, which can lead to neurological compromise. Failure is usually at the pin-bone interface. Thus, regular recalibration and replacement is necessary. Loosening of pins is also common with infection and these pins should not be retightened with risk of inner skull penetration. Inner skull calvarium penetration and pin site infection can lead to brain abscess or meningitis, which is associated with a mortality rate of $24 \%$ [26]. Injury to the temporal artery can also occur from the traction pins due to direct laceration or pin site invasion. The ideal pin site is at thickest skull bone located above external auditory meatus bilaterally. The area directly anterior and superior to the ear tragus should be avoided.

Overdistraction is dangerous in occipitocervical dislocations, odontoid fractures and hyperextension and distraction injuries. Cranial nerve injury involving the abducens, glossopharyngeal, vagus and hypoglossal nerves has also been reported to occur after traction with an incidence 
of $0.07 \%$ [27]. Causes include neuropraxia, ischaemia due to oedema, direct compression or stretching or kinking of the nerve. In patients with ligamental laxity, other complications include focal cervical kyphosis (16\%), loss of normal cervical lordosis (35\%) and atlantoaxial subluxation greater than $3 \mathrm{~mm}$ (20\%) [28]. This is explained by overdistraction and tensioning of the musculoligamentous element stretching beyond its elastic limit.

\section{Dural tear and CSF leak}

The risk of durotomy during laminectomy is $0.3 \%-13 \%$ and can be up to $18 \%$ with revision surgery $[29,30]$. Risk factors include old age, thin dura as a result of chronic compression, ossification of the ligamentum flavum, synovial cysts and scarring from prior surgery. The ligamentum flavum and posterior longitudinal ligaments are helpful barriers during decompression and these soft tissues should be carefully elevated after the overlying bone is removed. Incidental durotomies present as postural headache, nausea, vomiting, dizziness, photophobia, tinnitus and vertigo, but are typically asymptomatic. Symptoms are caused by intracranial hypotension leading to traction on the brain. Whenever possible, there should be attempts to repair the tears. Fat, fibrin glue or mesh coverage of the repair site should be performed to avoid damage to the repair site. Drains are not recommended in CSF leaks as they may encourage continuous CSF flow and delay dural healing, and re-exploration should only be performed for symptoms [31]. Persistent CSF leakage is associated with formation of CSF fistulas or pseudomeningoceles.

\section{Anterior Surgical Exposure}

\section{Recurrent laryngeal, superior laryngeal and hypo- glossal nerve injuries}

Vocal cord paralysis occurs in $0.0711 \%$ of cases. Most cases are transient, lasting weeks to months. But paralysis can be permanent in $0.153 .5 \%$ of cases [32-34]. Causes of injury include nerve division or ligature, ischaemia by pressure, neuropraxia by over-stretching and oedema due to surgical trauma. Of these, ischaemia is most common due to decreases in mucosal and neuronal capillary blood flow.

The safer side to approach the spine in relation to nerve palsy is controversial. Some studies have shown no difference between the side of approach and incidence of nerve palsy $[32,35]$ while another recommended a left-sided approach [36]. As most surgeons are right-handed, a rightsided approach allows technically easier disc access. In this approach, far lateral ligature of the inferior thyroid vessels should be avoided [37] and the risk of nerve injury increases below C4 [38]. In revision surgery, the other side should be used to minimise iatrogenic injury from exploring a scarred surgical field. However, approach from the same side is recommended in previous laryngeal nerve injury to avoid potential risk of bilateral vocal cord paralysis [39].

Technical considerations to avoid vocal cord paralysis include careful dissection and placement of the retractors under the longus colli muscle belly and avoidance of the tracheoesophageal groove. The longus colli should not be shredded during elevation to maintain a firm anchor point for placement of retractors. Sharp-toothed retractor blades are advised as they have better anchorage. Blunt tooth blades can easily slip. Displacement anteromedially can compress the trachea or oesophagus medially. Displacement anterolaterally can damage the carotid artery. This can be avoided by intermittent release of the retractors.

The endotracheal tube accounts for $11.2 \%$ of vocal cord paralysis [40]. The tube can impinge on the lateral laryngeal wall, compressing the submuscoal transversing (endolaryngeal) portion of the recurrent laryngeal nerve as it supplies the vocal cords. Cuff pressure release by balloon deflation can avoid compression of the inner laryngeal wall by the tube. Reinflation of the cuff to a just-sealed pressure is adequate for the surgery. Too much retraction pressure against the larynx should also be avoided as this can push against the endotracheal tube.

The superior laryngeal nerve $(\mathrm{C} 3-\mathrm{C} 4)$ can also be damaged via an anterior approach to the upper cervical spine. Patients complain of problems with high notes in singing with superior laryngeal nerve injury. Hypoglossal nerve injury during dissection of the anterior triangle of the neck at $\mathrm{C} 2-\mathrm{C} 4$ occurs in up to $8.6 \%$ of cases [41]. The nerve is especially at risk in high retropharyngeal approaches to the upper cervical spine where the nerve may traverse the field, resembling a blood vessel. Postoperative diagnosis is also difficult as palsy causes dysphagia and dysarthria, which are also symptoms associated with oesophageal or recurrent laryngeal nerve injury. 


\section{Oesophageal injury}

Iatrogenic dysphagia is usually transient with a reported postoperative incidence of $9.5 \%$ [13]. Intraoperative retraction of the oesophagus is the most common cause of postoperative dysphagia due to ischaemia of the pharyngeal/oesophageal wall. Thus, intermittent release of the retractors can avoid injury to the oesophagus. Other causes of dysphagia include oedema, haematoma, infection, injury to pharyngeal plexus, superior laryngeal nerve or recurrent laryngeal nerve, scar formation around cervical plates and bone graft dislodgement. In prolonged cases, swallowing integrity can be assessed by videofluoroscopy. Reduced movements of the pharyngeal wall, impaired upper oesophageal sphincter opening, incomplete epiglottic deflection and post-swallow residue in the vallecula, pyriform sinuses and posterior pharyngeal wall can be observed on swallowing studies [42].

Oesophageal perforation (Fig. 1) has an incidence of $0.2 \%-1.15 \%[34,43,44]$. To avoid this complication, blunt finger dissection is recommended for exposures below the superficial cervical fascia. Careful retraction to mobilise the oesophagus can help prevent injury. The region most at risk of perforation by screw back-out, implant loosening or migration is the cricopharyngeal region of the cervical oesophagus, where the posterior oesophageal mucosa is covered only by a thin fascial layer [45]. Delayed perforations are usually caused by erosions over a bony prominence, cement or implant. Complications secondary to oesophageal perforations include wound breakdown, malnutrition, mediastinitis, oesophageal stricture, osteomyelitis, pneumonia, prevertebral or retropharyngeal abscesses and tracheoesophageal fistulas [44]. Intraoperatively, methylene blue can be injected into the oral-pharyngeal tube to check for the site of perforation. Repair or flap coverage should be performed at the same setting.

Mortality can reach $50 \%$ with delayed treatment of oesophageal perforations $[43,44]$. Neck pain and crepitus should raise concern for oesophageal perforation and secondary infection. Other symptoms include dysphagia, hoarseness, aspiration, fever, leukocytosis and tachycardia. Lateral cervical spine radiographs can show subcutaneous emphysema, widening of retropharyngeal space due to soft tissue swelling or collection, prevertebral air and implant migration. Contrast pharyngoesophagography, flexible fibreoptic endoscopy and computed tomography (CT) are helpful in detecting the location and extent of perforation. Endoscopy can show the site of perforation and CT scans detect abscess and any graft displacement. Common organisms involved in post-oesophageal perforation infections are Streptococcus, Staphylococcus aureus, Pseudomonas, Bacteroides, anaerobic gram-positive cocci and Candida albicans [46].

\section{Vertebral and carotid artery injuries}

Injury to the vertebral artery ranges from $0.3 \%-0.5 \%$ $[47,48]$. The uncinate process should be identified as it
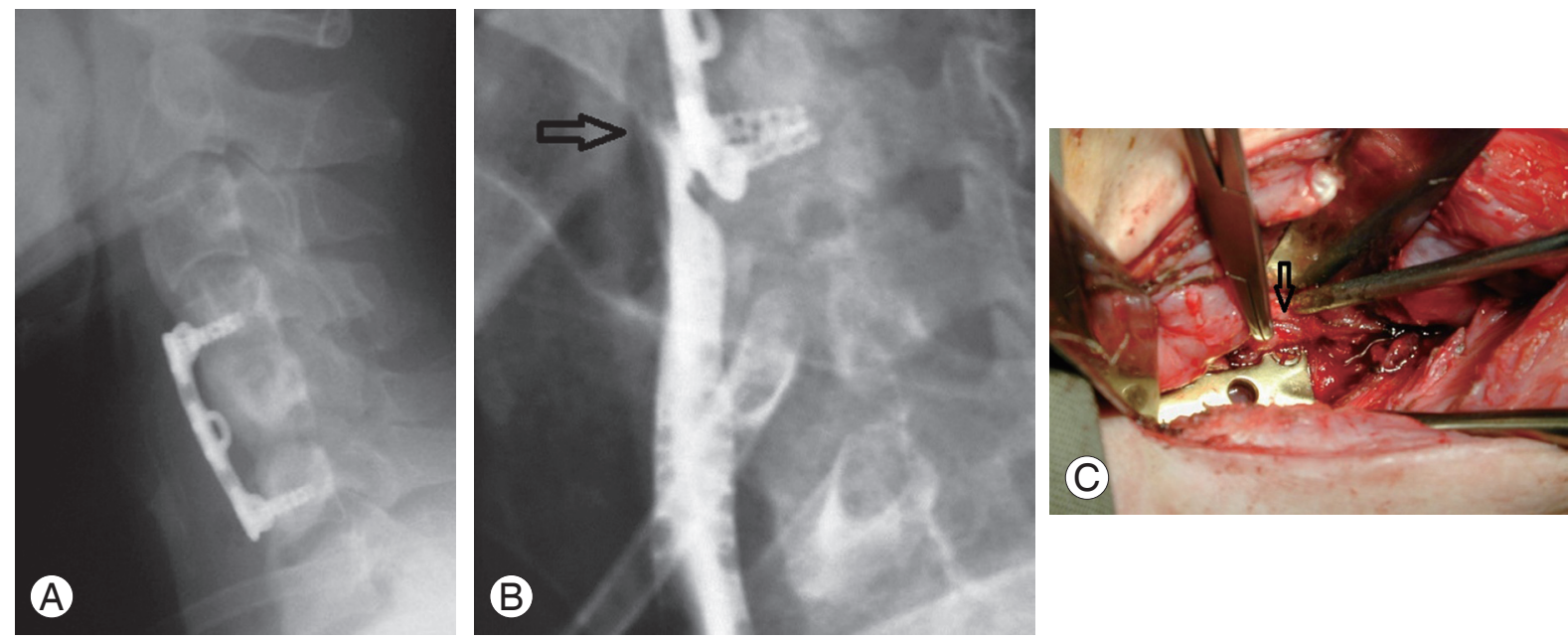

Fig. 1. (A) Postoperative lateral radiograph of a patient with anterior discectomy and fusion at $C 4 / 5$ and $C 5 / 6$. (B) Impingement of the lower screws at the esophagus caused a rupture with gastrograffin leakage from the esophagus (arrow). (C) Intraoperatively, esophageal rupture was noted at the site corresponding to the prominent screw head (arrow). This patient required a pectoralis major flap for coverage of the defect. 
locates the lateral border of the spinal canal. The medial aspect of the uncovertebral joint signifies the lateral extent for dissection or drilling, but the border may be obscured by osteophytes in degenerative cases. Ventral decompression should be no wider than 18-20 mm. Decompression of uncovertebral joints, neural foramen, lateral disc herniations and posterolateral corpectomy should be performed with care as these procedures can all damage the vertebral artery. Damage occurs most often during surgery anterior to transverse foramen of $\mathrm{C} 7$ or during lateral decompression maneuvers from C3 to C6. Careful identification of the longus colli and uncovertebral joints are crucial for midline dissections. With adequate collateral circulation, some patients may remain asymptomatic while others will have devastating vertebrobasilar ischaemia or fatal bleeding, and vascular embolic complications.

Injury to the carotid artery can result from improper surgical dissection and excessive retraction. Prolonged pressure against the carotid artery can cause thrombosis or cerebral ischaemia. Manipulation can also dislodge plaques, causing intracranial embolus and stroke. Use of duplex ultrasound has demonstrated that a $14 \%$ decrease in cross-sectional area occurs with placement of retractors, which reaches $30 \%$ at the end of surgery [49]. Preoperative carotid artery interventions may be considered in these cases.

\section{Tracheal injury}

Tracheal injury is life-threatening as the defect may allow the oesophagus to prolapse into the tracheal lumen causing acute asphyxia. It may be caused by intubation injury or direct surgical trauma. Other sequelae include mediastinitis, sepsis and tension pneumothorax [50]. There is also a chance of tracheal stenosis formation, tracheoesophageal fistula and surgical emphysaema. Longitudinal lacerations are less likely to produce stenosis and can be directly repaired, while others may warrant sternocleidomastoid muscle flap coverage [51].

\section{Miscellaneous injury}

Thoracic duct injury can occur during left-sided neck dissection. The thoracic duct can be identified dorsal to the subclavian vein and should be protected. Injury results in chylorrhea and chylous fistula presenting as skin flap erythema and oedema [52]. Chronic chyle loss leads to fluid, electrolyte and protein depletion, metabolic derangement, peripheral lymphocytopaenia and poor immunity. $\mathrm{Pa}$ tients may have progressive weakness, dehydration and peripheral oedema.

Cervical sympathetic chain injury and resultant ipsilateral Horner's syndrome (miosis, ptosis, anhidrosis) is rare (4.2\%) [33]. The cervical sympathetic chain travels between the carotid sheath and longus colli, and should be preserved in mid-cervical approaches. Any retraction of dissection lateral to the longus colli can cause injury.

Pharyngocutaneous fistulas are rare complications of anterior surgery $(<0.1 \%)[53]$ resulting from oesophageal perforations during dissection, using a burr for decompression and during instrumentation of the anterior cervical spine.

\section{Anterior Surgery}

\section{Injury to spinal cord and nerve roots}

Cord injury during decompression is rare but is a risk in the presence of significant stenosis. Injury is usually caused during osteophyte removal with Kerrison rongeurs or by drilling. Often this complication is detected postoperatively. Meticulous haemostasis, adequate illumination and visualisation, experience and proper technique are important to avoid this complication. Spinal cord injury can also be caused by inserting the bone graft after discectomy. Proper appropriate sizing, shaping and tapping the graft in place with proper depth and height can avoid bone graft extrusion. Electrophysiological monitoring using somatosensory and motor evoked potentials of the spinal cord is useful for monitoring during surgery and is especially useful in high-risk patients who have preexisting cord contusion or severe stenosis [54]. Preoperative baselines should be obtained in patients for comparison.

\section{Corpectomy}

The overall morbidity risk associated with corpectomy is $11 \%-27 \%$ and is most commonly caused by postoperative dysphagia, haematoma and recurrent laryngeal nerve palsy [55-58]. Despite the high rate of complications, mortality is low (0.1\%) [13]. Unlike discectomy, corpectomies carry a greater risk of graft migration, strut graft dislodgement, infection and pseudoarthrosis due to larger 
destabilization of the anterior column [59]. Other complications include graft pistoning, mortise penetration, inadequate deformity correction and failure of fixation and neurological compromise. Late complications include graft fracture, collapse or subsidence and non-union.

Most graft dislodgement occurs soon after surgery (within 24 hours). Graft migration rates increase appreciably with each additional fusion level, with a reported odds ratio of 1.65 [60]. In this study, most dislodgements occurred at the C6 level and extension to C7 level in 14 of 16 patients, with five patients requiring revision surgery. Common causes for graft dislodgement are poor bone quality and increased stress at the graft-endplate interface at the cervicothoracic junction; the change from cervical lordosis to thoracic kyphosis increases the risk of graft extrusion. If posterior elements are deficient, such as post-laminectomy, greater compression and shear loads through the strut graft increases the risk of fracture, subsidence and dislodgement. Two or three level corpectomies and deficient posterior elements warrant additional posterior instrumentation and fusion for a stronger mechanical construct. Supplemental external immobilisation with a halo vest can theoretically increase the rigidity of the construct and decrease the chance of cage dislodgment, especially in long fusions. Partial dislodgement may be closely observed but total dislodgement requires another operation as there is risk of oesophageal irritation or penetration with subsequent mediastinal infection. Revision posterior instrumentation and fusion should be performed in anterior multi-level fusion collapse or graft subsidence, especially in cases of osteopenia. Graft subsidence with mortise penetration presents with loss of graft height and endplate penetration. This may result in kyphosis, loss of structural integrity and muscle spasms due to the sagittal imbalance. Neurological compromise can even occur if the spinal cord is pressed against the apex of the kyphotic deformity. Selecting patients with only single or adjacent two level decompression, and without significant osteoporosis or needed correction of kyphosis can help prevent these catastrophic complications.

Anterior plating reduces the motion around the corpectomy site and improves the construct stability. However, the center of rotation will be shifted to the anterior surface of the cervical vertebrae where the plate is located. Any graft subsidence will transfer all compressive loads to the plate, leading to failure. The site of failure usually occurs at the lower junction construct resulting in plate and strut graft dislodgement. These cases also require additional posterior support as plating is rarely strong enough on its own. Dynamic plates theoretically allow continued contact between the graft and the endplate after graft subsidence, which improves the chance of obtaining fusion by compressive load on the graft. However, segmental kyphosis may occur. Results are controversial with reports of higher nonunion rates with dynamic plates $(16 \%)$ versus static plates (5\%) due to failure of angular motion between screws and plates [61].

Graft displacement and subsidence are important problems with anterior surgery. Prevention requires good patient selection and surgical technique. Younger patients without renal failure or steroid use are generally preferred due to their bone quality. Good preparation of the graft, obtaining parallel fusion beds and sitting the graft under load from the cortical bone are important steps to ensure the maximum stability for fusion. Two or three level corpectomies destabilizes the anterior column support and should be supplemented by posterior instrumentation.

\section{Ossified posterior longitudinal ligament (OPLL)}

In surgery for OPLL, the reported postoperative incidence is $2 \%-10 \%$ for quadriplegia and $5 \%-17 \%$ for root injury (usually involving C5) [62]. An anterior approach can directly remove the ossified ligament but is generally not recommended due to the technical difficulties and risk of dural tear, epidural venous bleeding and cord injury. If an anterior approach is chosen, due to usual adherence to the dura, anterior ossified lesions are commonly left alone if adequate floating cord is achieved. More lateral decompression is required as the OPLL expands laterally at the intervertebral disc level. This also carries the risk of injuring the vertebral artery if exploration is lateral to the uncinate process.

\section{Adjacent segment degeneration (ASD)}

Up to $15 \%$ of anterior cervical discectomy and fusion cases [63-65] and 9\% of all posterior surgeries develop ASD [66]. A 21-year follow-up study of 409 procedures for 374 patients reported a $13.6 \%$ prevalence of symptomatic ASD at 5 years and $25.6 \%$ at 10 years [63]. In the study, the risk of developing adjacent segment disease was $3 \%$ per patient per year. Fusionless surgery is less likely to develop ASD. Plating can hasten ASD if it is placed within 
$5 \mathrm{~mm}$ of the adjacent cranial disc segment and should be avoided [67].

\section{Pseudoarthrosis}

The incidence of pseudoarthrosis varies widely from 0\%-50\% [68-73]. Risks include smoking, osteoporosis, increased fusion levels, poor surgical technique, use of antimetabolic agents including phenytoin, non-steroidal anti-inflammatory agents (some are avoided for at least 10 weeks as they reduce osteoblastic activity), collagen disorders and location of fusion. Bone substitutes like bone morphogenetic proteins (BMP) are commonly used to improve fusion rates [74]. However, serious complications associated with BMP include heterotopic ossification that forms near the spinal canal or neuroforamen in 20.8-75\% of patients $[75,76]$ and vertebral osteolysis in $82 \%$ of cases [77,78]. Other complications include massive airway oedema, discharging wound seroma, haematoma formation and radiculopathy resulting from increased inflammation [79]. In general, BMP should be used cautiously. Surgeons should avoid overdosing and avoid placing BMP in sensitive areas, such as behind the oesophagus.

\section{Cervical disc arthroplasty}

The value of cervical disc arthroplasty is debatable. A recent randomised controlled trial with a 5 -year postoperative follow-up reported greater improvement in objective outcome scores with a lower rate of ASD and secondary surgical procedures for cervical disc arthroplasty as compared to anterior cervical discectomy and fusion [80]. General complications are similar between fusion and disc replacement. Some specific complications related to arthroplasty include prosthesis malpositioning and displacement, subsidence and heterotopic ossification [81]. Careful patient selection is important to improve success rates. General recommendations for disc arthroplasty include lesions at C3-C7, single or two adjacent levels, more for radiculopathy and avoidance of chronic myelopathy. Patients with osteoporosis should avoid arthroplasties as good bone quality allows for tighter prosthesis fitting. Patients with facet degeneration and severe vertebral collapse should not have arthroplasties performed. Technically, near perfect sizing of the implant should be done along with parallel pin placement and adequate decompression of the neural structures.

\section{Posterior Surgery}

\section{Injury to spinal cord and nerve roots}

The overall incidence of neurological complications has been reported as $0.18 \%$ [82] and increases with severe cervical kyphosis correction (2.6\%) [83]. Late neurological complications can be avoided in posterior corrective surgery for cervical kyphosis by prophylactic foraminotomies in the presence of foraminal stenosis, kyphosis correction that does not exceed $9.7^{\circ}$ per spinal segment and avoiding kyphosis correction at $\mathrm{C} 4-\mathrm{C} 5$, which is where the largest posterior shift of the spinal cord occurs leading to C5 palsy $[83,84]$. This is a common problem but most cases resolve spontaneously. Similar to anterior surgery, spinal cord monitoring is a good adjunct monitoring tool.

\section{Screw fixation}

Screw malposition varies from $0 \%-4 \%$ in the atlas and $0 \%-7 \%$ in the axis [85-87]. Transarticular C1-C2 screws or Magerl screws pose an additional risk of vertebral artery injury, neurological deficit or inadequate bony purchase (Fig. 2). Vertebral artery injury is one of the most dangerous complications of screw fixation and is usually due to incorrect cervical pedicle screw entry with vertebral artery injury. The incidence of iatrogenic vertebral artery injury is $1.3 \%-4 \%$ for Magerl fixation [88]. Fortunately, the risk of neurological deficit is low (0.2\%) [89]. Mortality is greatly increased if both vertebral arteries are injured. Lateral deviation of screws can often lead to penetration of the foramen transversalis and subsequent vertebral artery injury [90]. Current trends include the use of intraoperative CT and computer-assisted navigation systems to improve screw trajectory and reduce screw perforation $[91,92]$.

Subaxial lateral mass screws carry a risk of nerve root injury (1.3\%) and lateral mass fracture [93]. Direct root injury during lateral mass screw insertion can be avoided with fluoroscopic control. Insertion under sagittal angulations of less than $15^{\circ}$ may lead to impingement of the exiting nerve root by the protruding screw threads (Fig. 3) [93]. In axial trajectories greater than $30^{\circ}$ lateral to the midline, lateral mass fracture (1.6\%) or screw cut-out (1.3\%) may occur [93]. However, neurological harm is not common. Screws placed too medially can cause vertebral artery injury. 

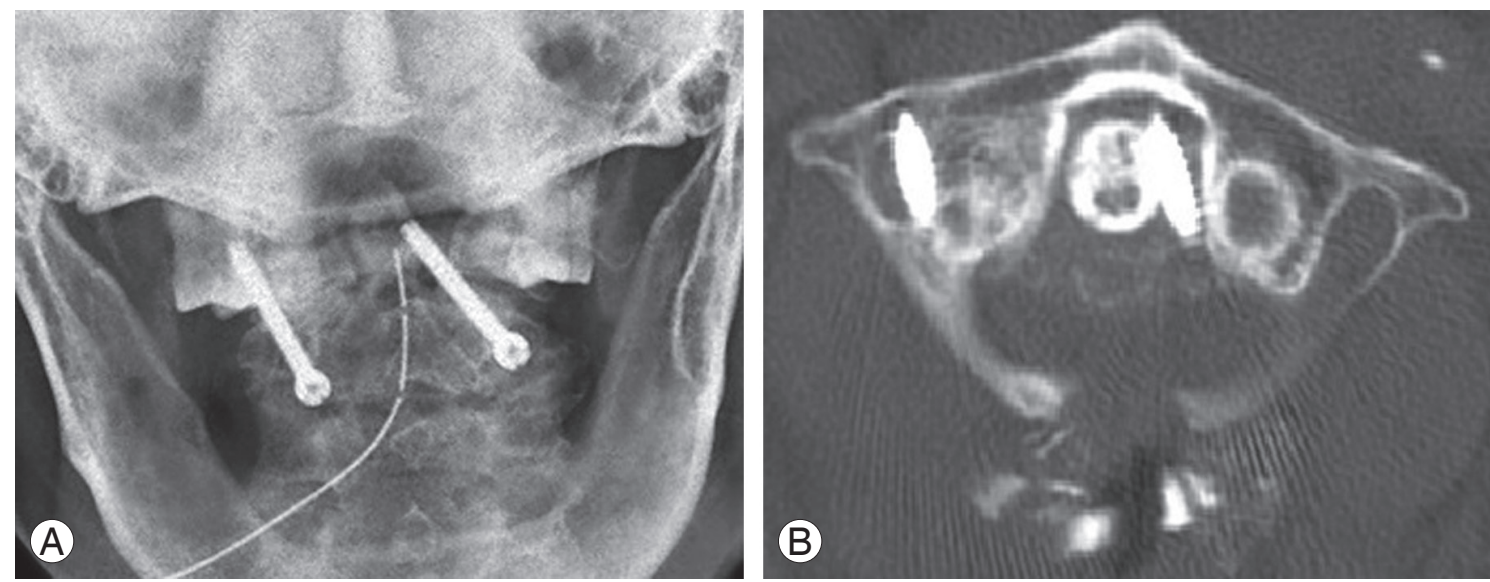

Fig. 2. Postoperative observations with transarticular C1-C2 screws. (A) Open mouth view showed misdirected screws with the right screw inserted too laterally and the left screw inserted too medially. (B) Axial computed tomography at the level of the atlas shows that the right screw has penetrated the foramen transversalis, likely injuring the vertebral artery and the left screw has penetrated too medially into the spinal canal. Fortunately, the patient did not develop stroke but these screws required revision surgery.
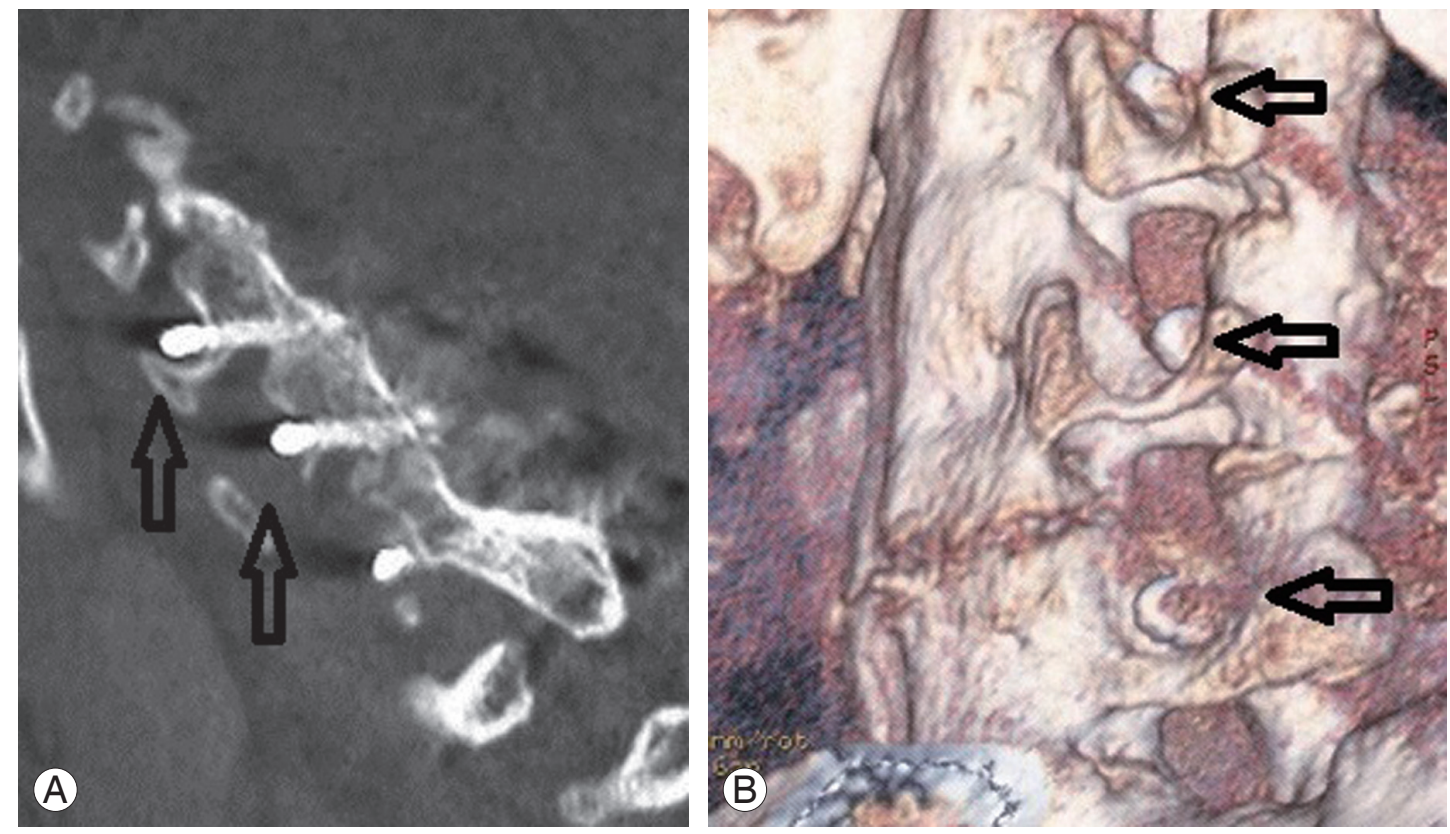

Fig. 3. Postoperative (A) lateral computed tomography (CT) scans and (B) three-dimensional CT reconstruction showing penetration of the lateral mass screw into the exiting nerve root foramen (arrows). As the patient was asymptomatic, these screws were left in-situ.

\section{Posterior occiptocervical instrumentation}

In occipitocervical instrumentation, precise insertion of the occipital screws is crucial to prevent complications. Any screws inserted cephalad to the superior nuchal line can injure the transverse sinus. Loosening of screws is noted in $4.2 \%-7 \%$ of cases and dural tears occur at a range from $0 \%-4.2 \%$ during drilling of the occiput and screw placement $[94,95]$. This area of the scalp is also quite thin and skin erosions due to prominent implants can occur. Dural laceration can occur during burr hole drilling of the occiput or wire recoil with wire-based fixation (25\%-28\%) $[95,96]$. Dural laceration leads to CSF leak but screw insertions into the drill hole are usually sufficient to halt a CSF leak. Late complications of occipitocervical fusion include pseudoarthrosis (6\%) and adjacent level degeneration (7\%) [97]. 


\section{C5 palsy}

Yonenobu et al. [62] reported a 3.4\% incidence of early postoperative C5 nerve root deterioration. These injuries are usually motor-dominant but may also have sensory and radicular pain. C5 dysfunction can occur immediately to 20 days postoperatively [98]. Recovery usually occurs but takes weeks, months or as long as 6 years [99]. Traction injuries to the nerve root are the likely cause due to the posterior shift of the decompressed cord. The C5 root is at risk due to its direct and short course as it exits the spinal cord. It is also at the apex of lordosis. Hence, the distance of cord shift and root traction is greatest. With a posterior drift, C5 root tethering occurs and may be stretched beyond its tolerance limit. The deltoid has a single innervation by the $\mathrm{C} 5$ nerve root, so any nerve dysfunction has a profound effect on patient function. Prophylactic foraminotomy should be considered in cases of pre-existing deltoid weakness, intervertebral foraminal stenosis, OPLL and laminectomy with instrumentation [100].

\section{Spring-back closure}

Spring-back closure after laminoplasty (Fig. 4) has a reported rate of $40 \%$ [101]. However, this complication has only been reported with suture fixation and has yet to be observed in modern screw or plate fixation. Lee et al. [102] found that at 6 months postoperatively, the anteroposterior diameter increase after surgery and opening angle (angle between line connecting medial end of bilateral facet joint and the line connecting the bilateral end of the opened lamina) is reduced by approximately $10 \%$ for patients with Hirabayashi open-door laminoplasty. For double-door laminoplasty, postoperative migration of the spinal cord between the split laminae may cause

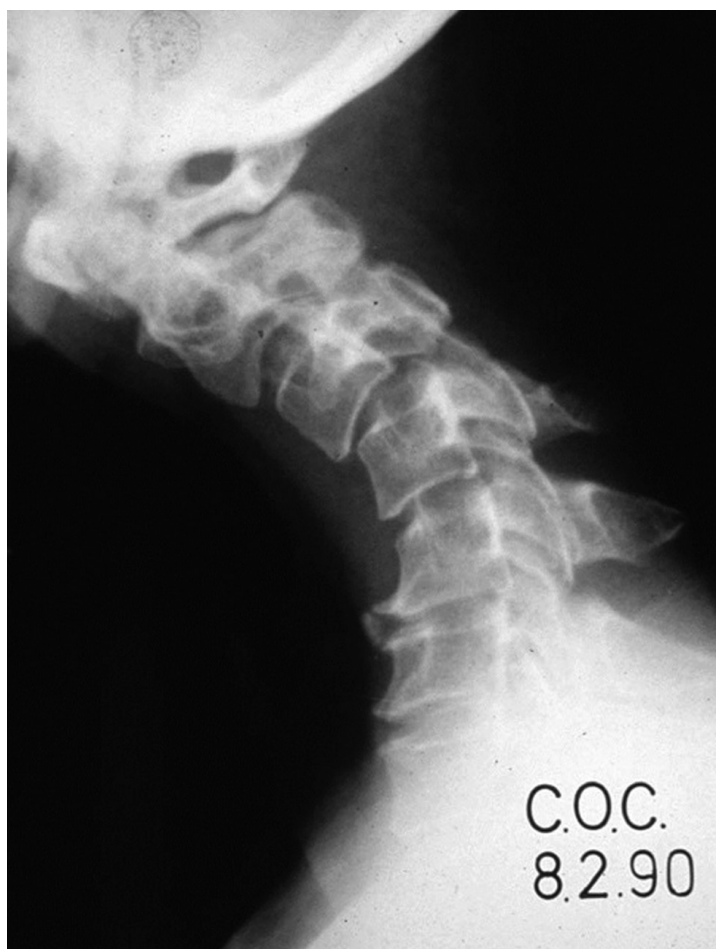

Fig. 5. Lateral radiograph of a patient after C2-4 laminectomy with subsequent kyphosis. Revision posterior instrumentation and fusion was required.
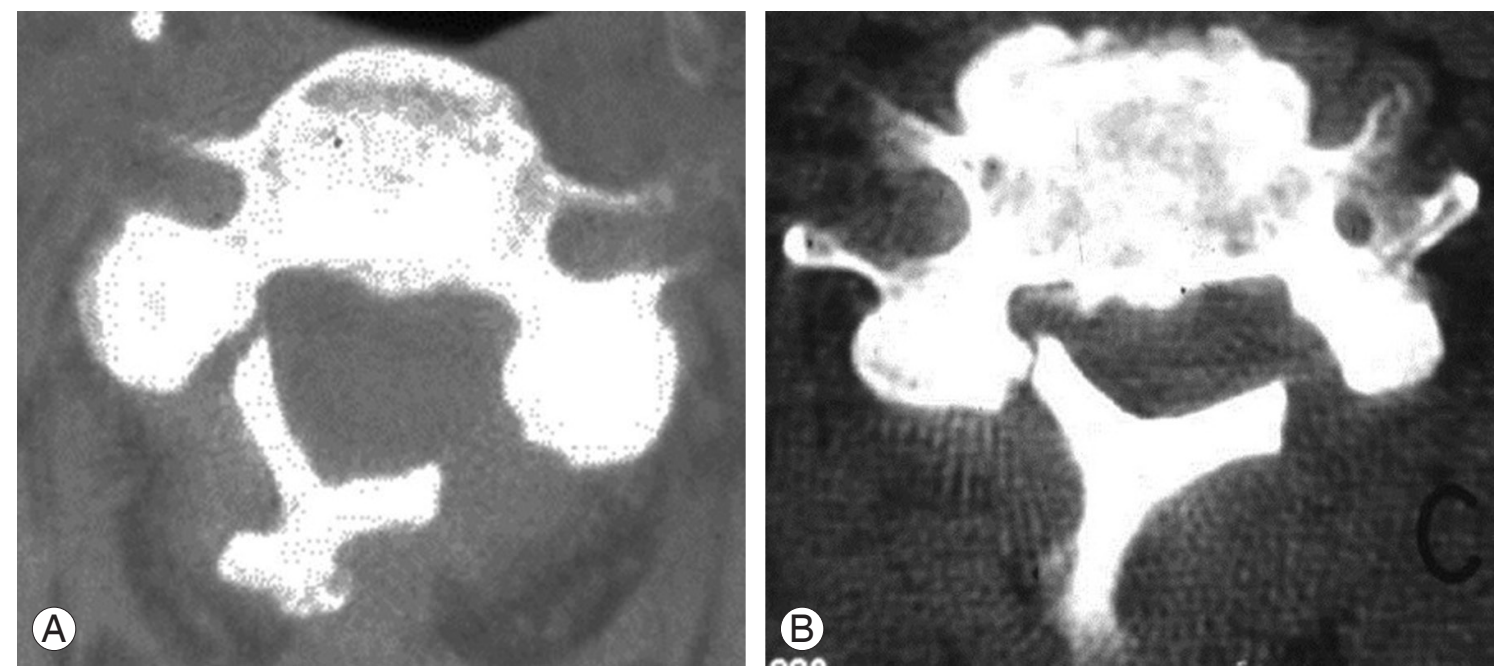

Fig. 4. Axial computed tomography scans showing (A) hinge fracture after laminoplasty and (B) springback closure. Revision laminectomy and fusion was performed. 
worsening myelopathy.

\section{Postlaminectomy kyphosis}

The incidence of kyphosis deformity after multilevel laminectomy (Fig. 5) is 20\% [103]. Older patients may have partially fused cervical spines and are more stable. Thus, postoperative kyphosis is more common in younger patients. Laminectomy includes removal of the spinous processes, inter and supraspinous ligaments, laminae and ligamentum flavum and loss of capsules of facet joints that compromise the posterior stabilizers. Continuing normal flexion forces results in kyphosis. Kyphosis develops gradually, which is why patients are usually well in the early postoperative period. Constant contraction of neck extensor muscles will occur, causing muscle fatigue and neck pain. Progressive kyphosis in children leads to anterior vertebral wedging due to compression of growing cartilaginous endplates. Sagittal malalignment and axial neck pain are the main issues regarding postlaminectomy kyphosis while neurological deficit is rarely encountered. Traction often can restore the cervical alignment to the immediate postoperative alignment in the early postoperative period. Laminectomy should be avoided in young patients without cervical lordosis. Posterior facet joints should not be disrupted intraoperatively. Fusion should be considered for these patients at the same procedure.

\section{Minimally invasive surgery}

Minimally invasive surgery has not gained widespread acceptance in the cervical spine despite the advantages of reduced muscle retraction, blood loss and postoperative pain. The limited visualisation offered by minimally invasive surgery may lead to more severe complications. Manipulation in a tight neural foramen can cause root injury. Direct spinal cord injury may also occur during dilation or decompression. During surgery, careful insertion of the blunt dilator using fluoroscopic imaging is advised to prevent it from entering the interlaminar space, resulting in nerve injury. Dural tears have been reported in $1.6 \%-6.6 \%$ of minimally invasive decompression procedures [104-107]. With dural injury, repair is more difficult with limited access and exposure provided by the small tubular retractor and conversion to open surgery is usually required.

\section{Conclusions}

Despite the benefits of cervical surgery for treating the appropriate pathologies, there are still many possible complications. These begin with the anaesthesia and positioning to the surgical dissection and procedure. In anterior surgery, avoiding prolonged and forceful retractions can prevent injury to the oesophagus, recurrent laryngeal nerve and carotid arteries. Additional protection of corpectomies with plating combined with posterior spinal fusion and instrumentation can help reduce rates of graft dislodgements. Careful selection of patients for corpectomy is also important as graft collapse and subsidence commonly occurs with osteopenic bone. In posterior surgery, prophylactic foraminotomy may help reduce the risk postoperative C5 nerve root palsy. Spinal cord monitoring is advocated in all cases of cervical spine surgery. Careful analysis of the bony and vascular anatomy should be done preoperatively, especially when internal fixation is contemplated. Preservation of posterior muscles and their attachments are important for prevention of postoperative neck pain and delayed kyphosis. Most complications are manageable with adequate preparation. When carefully and properly executed, cervical spine surgery can be effective with an acceptable rate of complications.

\section{Conflict of Interest}

No potential conflict of interest relevant to this article was reported.

\section{References}

1. Emery SE, Smith MD, Bohlman HH. Upper-airway obstruction after multilevel cervical corpectomy for myelopathy. J Bone Joint Surg Am 1991;73:544-51.

2. McAfee PC, Bohlman HH, Ducker TB, Zeidman SM, Goldstein JA. One-stage anterior cervical decompression and posterior stabilization: a study of one hundred patients with a minimum of two years of followup. J Bone Joint Surg Am 1995;77:1791-800.

3. Sagi HC, Beutler W, Carroll E, Connolly PJ. Airway complications associated with surgery on the anterior cervical spine. Spine (Phila Pa 1976) 2002;27:949-53.

4. Zdeblick TA, Bohlman HH. Cervical kyphosis and myelopathy: treatment by anterior corpectomy and strut-grafting. J Bone Joint Surg Am 1989;71:170-82. 
5. Krengel WF 3rd, Robinson LR, Schneider VA. Combined effects of compression and hypotension on nerve root function: a clinical case. Spine (Phila Pa 1976) $1993 ; 18: 306-9$.

6. Naito M, Owen JH, Bridwell KH, Sugioka Y. Effects of distraction on physiologic integrity of the spinal cord, spinal cord blood flow, and clinical status. Spine (Phila Pa 1976) 1992;17:1154-8.

7. Kakiuchi M. Intraoperative blood loss during cervical laminoplasty correlates with the vertebral intraosseous pressure. J Bone Joint Surg Br 2002;84:518-20.

8. Younger EM, Chapman MW. Morbidity at bone graft donor sites. J Orthop Trauma 1989;3:192-5.

9. Sasso RC, Williams JI, Dimasi N, Meyer PR Jr. Postoperative drains at the donor sites of iliac-crest bone grafts: a prospective, randomized study of morbidity at the donor site in patients who had a traumatic injury of the spine. J Bone Joint Surg Am 1998;80:631-5.

10. Arrington ED, Smith WJ, Chambers HG, Bucknell AL, Davino NA. Complications of iliac crest bone graft harvesting. Clin Orthop Relat Res 1996;(329): 300-9.

11. Ebraheim NA, Elgafy H, Xu R. Bone-graft harvesting from iliac and fibular donor sites: techniques and complications. J Am Acad Orthop Surg 2001;9:210-8.

12. Meeder PJ, Eggers C. Techniques for obtaining autogenous bone graft. Injury 1994;25 Suppl 1:A5-16.

13. Fountas KN, Kapsalaki EZ, Nikolakakos LG, et al. Anterior cervical discectomy and fusion associated complications. Spine (Phila Pa 1976) 2007;32:2310-7.

14. Rawlings CE 3rd, Wilkins RH, Gallis HA, Goldner JL, Francis R. Postoperative intervertebral disc space infection. Neurosurgery 1983;13:371-6.

15. Cruse PJ, Foord R. A five-year prospective study of 23,649 surgical wounds. Arch Surg 1973;107:206-10.

16. Wimmer C, Gluch H, Franzreb M, Ogon M. Predisposing factors for infection in spine surgery: a survey of 850 spinal procedures. J Spinal Disord 1998;11: 124-8.

17. Caroom C, Tullar JM, Benton EG Jr, Jones JR, Chaput $\mathrm{CD}$. Intrawound vancomycin powder reduces surgical site infections in posterior cervical fusion. Spine (Phila Pa 1976) 2013;38:1183-7.

18. Levi AD, Dickman CA, Sonntag VK. Management of postoperative infections after spinal instrumentation. J Neurosurg 1997;86:975-80.

19. Weinstein MA, McCabe JP, Cammisa FP Jr. Postop- erative spinal wound infection: a review of 2,391 consecutive index procedures. J Spinal Disord 2000;13: 422-6.

20. Richards BS, Herring JA, Johnston CE, Birch JG, Roach JW. Treatment of adolescent idiopathic scoliosis using Texas Scottish Rite Hospital instrumentation. Spine (Phila Pa 1976) 1994;19:1598-605.

21. Garfin SR, Botte MJ, Waters RL, Nickel VL. Complications in the use of the halo fixation device. J Bone Joint Surg Am 1986;68:320-5.

22. Dormans JP, Criscitiello AA, Drummond DS, Davidson RS. Complications in children managed with immobilization in a halo vest. J Bone Joint Surg Am 1995;77:1370-3.

23. Copley LA, Pepe MD, Tan V, et al. A comparative evaluation of halo pin designs in an immature skull model. Clin Orthop Relat Res 1998;(357):212-8.

24. Copley LA, Dormans JP, Pepe MD, Tan V, Browne $\mathrm{RH}$. Accuracy and reliability of torque wrenches used for halo application in children. J Bone Joint Surg Am 2003;85:2199-204.

25. Loder RT. Skull thickness and halo-pin placement in children: the effects of race, gender, and laterality. J Pediatr Orthop 1996;16:340-3.

26. Williams FH, Nelms DK, McGaharan KM. Brain abscess: a rare complication of halo usage. Arch Phys Med Rehabil 1992;73:490-2.

27. MacEwen GD, Bunnell WP, Sriram K. Acute neurological complications in the treatment of scoliosis: a report of the Scoliosis Research Society. J Bone Joint Surg Am 1975;57:404-8.

28. Hobbs WR, Sponseller PD, Weiss AP, Pyeritz RE. The cervical spine in Marfan syndrome. Spine (Phila Pa 1976) 1997;22:983-9.

29. Epstein NE, Hollingsworth R. Anterior cervical micro-dural repair of cerebrospinal fluid fistula after surgery for ossification of the posterior longitudinal ligament. Technical note. Surg Neurol 1999;52:511-4.

30. Smith MD, Bolesta MJ, Leventhal M, Bohlman HH. Postoperative cerebrospinal-fluid fistula associated with erosion of the dura: findings after anterior resection of ossification of the posterior longitudinal ligament in the cervical spine. J Bone Joint Surg Am 1992;74:270-7.

31. Khazim R, Dannawi Z, Spacey K, et al. Incidence and treatment of delayed symptoms of CSF leak following lumbar spinal surgery. Eur Spine J 2015;24:2069-76. 
32. Beutler WJ, Sweeney CA, Connolly PJ. Recurrent laryngeal nerve injury with anterior cervical spine surgery risk with laterality of surgical approach. Spine (Phila Pa 1976) 2001;26:1337-42.

33. Flynn TB. Neurologic complications of anterior cervical interbody fusion. Spine (Phila Pa 1976) 1982;7: 536-9.

34. Tew JM Jr, Mayfield FH. Complications of surgery of the anterior cervical spine. Clin Neurosurg 1976; 23:424-34.

35. Kilburg C, Sullivan HG, Mathiason MA. Effect of approach side during anterior cervical discectomy and fusion on the incidence of recurrent laryngeal nerve injury. J Neurosurg Spine 2006;4:273-7.

36. Jung A, Schramm J. How to reduce recurrent laryngeal nerve palsy in anterior cervical spine surgery: a prospective observational study. Neurosurgery 2010; 67:10-5.

37. Ebraheim NA, Lu J, Skie M, Heck BE, Yeasting RA. Vulnerability of the recurrent laryngeal nerve in the anterior approach to the lower cervical spine. Spine (Phila Pa 1976) 1997;22:2664-7.

38. Miscusi M, Bellitti A, Peschillo S, Polli FM, Missori $\mathrm{P}$, Delfini R. Does recurrent laryngeal nerve anatomy condition the choice of the side for approaching the anterior cervical spine? J Neurosurg Sci 2007;51:61-4.

39. Paniello RC, Martin-Bredahl KJ, Henkener LJ, Riew KD. Preoperative laryngeal nerve screening for revision anterior cervical spine procedures. Ann Otol Rhinol Laryngol 2008;117:594-7.

40. Yamada M, Hirano M, Ohkubo H. Recurrent laryngeal nerve paralysis: a 10-year review of 564 patients. Auris Nasus Larynx 1983;10 Suppl:S1-15.

41. Weiss K, Kramar R, Firt P. Cranial and cervical nerve injuries: local complications of carotid artery surgery. J Cardiovasc Surg (Torino) 1987;28:171-5.

42. Martin RE, Neary MA, Diamant NE. Dysphagia following anterior cervical spine surgery. Dysphagia 1997;12:2-8.

43. Gaudinez RF, English GM, Gebhard JS, Brugman JL, Donaldson DH, Brown CW. Esophageal perforations after anterior cervical surgery. J Spinal Disord 2000; 13:77-84.

44. Newhouse KE, Lindsey RW, Clark CR, Lieponis J, Murphy MJ. Esophageal perforation following anterior cervical spine surgery. Spine (Phila Pa 1976) 1989;14:1051-3.
45. Jones WG 2nd, Ginsberg RJ. Esophageal perforation: a continuing challenge. Ann Thorac Surg 1992;53: 534-43.

46. Rueth N, Shaw D, Groth S, et al. Management of cervical esophageal injury after spinal surgery. Ann Thorac Surg 2010;90:1128-33.

47. Golfinos JG, Dickman CA, Zabramski JM, Sonntag VK, Spetzler RF. Repair of vertebral artery injury during anterior cervical decompression. Spine (Phila Pa 1976) 1994;19:2552-6.

48. Smith MD, Emery SE, Dudley A, Murray KJ, Leventhal M. Vertebral artery injury during anterior decompression of the cervical spine: a retrospective review of ten patients. J Bone Joint Surg Br 1993;75: 410-5.

49. Pollard ME, Little PW. Changes in carotid artery blood flow during anterior cervical spine surgery. Spine (Phila Pa 1976) 2002;27:152-5.

50. Kaloud H, Smolle-Juettner FM, Prause G, List WF. Iatrogenic ruptures of the tracheobronchial tree. Chest 1997;112:774-8.

51. Couraud L, Jougon JB, Velly JF. Surgical treatment of nontumoral stenoses of the upper airway. Ann Thorac Surg 1995;60:250-9.

52. Hart AK, Greinwald JH Jr, Shaffrey CI, Postma GN. Thoracic duct injury during anterior cervical discectomy: a rare complication. Case report. J Neurosurg 1998;88:151-4.

53. Orlando ER, Caroli E, Ferrante L. Management of the cervical esophagus and hypofarinx perforations complicating anterior cervical spine surgery. Spine (Phila Pa 1976) 2003;28:E290-5.

54. Kelleher MO, Tan G, Sarjeant R, Fehlings MG. Predictive value of intraoperative neurophysiological monitoring during cervical spine surgery: a prospective analysis of 1055 consecutive patients. J Neurosurg Spine 2008;8:215-21.

55. Harsh GRt, Sypert GW, Weinstein PR, Ross DA, Wilson CB. Cervical spine stenosis secondary to ossification of the posterior longitudinal ligament. J Neurosurg 1987;67:349-57.

56. Kojima T, Waga S, Kubo Y, Kanamaru K, Shimosaka S, Shimizu T. Anterior cervical vertebrectomy and interbody fusion for multi-level spondylosis and ossification of the posterior longitudinal ligament. Neurosurgery 1989;24:864-72.

57. Saunders RL. Anterior reconstructive procedures 
in cervical spondylotic myelopathy. Clin Neurosurg 1991;37:682-721.

58. Saunders RL, Bernini PM, Shirreffs TG Jr, Reeves AG. Central corpectomy for cervical spondylotic myelopathy: a consecutive series with long-term followup evaluation. J Neurosurg 1991;74:163-70.

59. Hilibrand AS, Fye MA, Emery SE, Palumbo MA, Bohlman HH. Increased rate of arthrodesis with strut grafting after multilevel anterior cervical decompression. Spine (Phila Pa 1976) 2002;27:146-51.

60. Wang JC, Hart RA, Emery SE, Bohlman HH. Graft migration or displacement after multilevel cervical corpectomy and strut grafting. Spine (Phila Pa 1976) 2003;28:1016-21.

61. DuBois CM, Bolt PM, Todd AG, Gupta P, Wetzel FT, Phillips FM. Static versus dynamic plating for multilevel anterior cervical discectomy and fusion. Spine J 2007;7:188-93.

62. Yonenobu K, Hosono N, Iwasaki M, Asano M, Ono K. Neurologic complications of surgery for cervical compression myelopathy. Spine (Phila Pa 1976) 1991; 16:1277-82.

63. Hilibrand AS, Carlson GD, Palumbo MA, Jones PK, Bohlman HH. Radiculopathy and myelopathy at segments adjacent to the site of a previous anterior cervical arthrodesis. J Bone Joint Surg Am 1999;81:51928.

64. Ishihara H, Kanamori M, Kawaguchi Y, Nakamura $\mathrm{H}$, Kimura T. Adjacent segment disease after anterior cervical interbody fusion. Spine J 2004;4:624-8.

65. Kulkarni V, Rajshekhar V, Raghuram L. Accelerated spondylotic changes adjacent to the fused segment following central cervical corpectomy: magnetic resonance imaging study evidence. J Neurosurg 2004;100:2-6.

66. Henderson CM, Hennessy RG, Shuey HM Jr, Shackelford EG. Posterior-lateral foraminotomy as an exclusive operative technique for cervical radiculopathy: a review of 846 consecutively operated cases. Neurosurgery 1983;13:504-12.

67. Kim HJ, Kelly MP, Ely CG, Dettori JR, Riew KD. The risk of adjacent-level ossification development after surgery in the cervical spine: are there factors that affect the risk? A systematic review. Spine (Phila Pa 1976) 2012;37:S65-74.

68. Aronson N, Filtzer DL, Bagan M. Anterior cervical fusion by the smith-robinson approach. J Neurosurg
1968:29:396-404.

69. Bohlman HH, Emery SE, Goodfellow DB, Jones PK. Robinson anterior cervical discectomy and arthrodesis for cervical radiculopathy. Long-term follow-up of one hundred and twenty-two patients. J Bone Joint Surg Am 1993;75:1298-307.

70. Emery SE, Bolesta MJ, Banks MA, Jones PK. Robinson anterior cervical fusion comparison of the standard and modified techniques. Spine (Phila Pa 1976) 1994;19:660-3.

71. Epstein NE. Evaluation and treatment of clinical instability associated with pseudoarthrosis after anterior cervical surgery for ossification of the posterior longitudinal ligament. Surg Neurol 1998;49:246-52.

72. Epstein NE. Anterior cervical diskectomy and fusion without plate instrumentation in 178 patients. J Spinal Disord 2000;13:1-8.

73. Riley LH Jr, Robinson RA, Johnson KA, Walker AE. The results of anterior interbody fusion of the cervical spine: review of ninety-three consecutive cases. J Neurosurg 1969;30:127-33.

74. Dimar JR, Glassman SD, Burkus KJ, Carreon LY. Clinical outcomes and fusion success at 2 years of single-level instrumented posterolateral fusions with recombinant human bone morphogenetic protein-2/ compression resistant matrix versus iliac crest bone graft. Spine (Phila Pa 1976) 2006;31:2534-9.

75. Haid RW Jr, Branch CL Jr, Alexander JT, Burkus JK. Posterior lumbar interbody fusion using recombinant human bone morphogenetic protein type 2 with cylindrical interbody cages. Spine J 2004;4:527-38.

76. Joseph V, Rampersaud YR. Heterotopic bone formation with the use of rhBMP2 in posterior minimal access interbody fusion: a CT analysis. Spine (Phila Pa 1976) 2007;32:2885-90.

77. Toth JM, Boden SD, Burkus JK, Badura JM, Peckham SM, McKay WF. Short-term osteoclastic activity induced by locally high concentrations of recombinant human bone morphogenetic protein-2 in a cancellous bone environment. Spine (Phila Pa 1976) 2009; 34:539-50.

78. Vaidya R, Sethi A, Bartol S, Jacobson M, Coe C, Craig JG. Complications in the use of rhBMP-2 in PEEK cages for interbody spinal fusions. J Spinal Disord Tech 2008;21:557-62.

79. Tannoury CA, An HS. Complications with the use of bone morphogenetic protein 2 (BMP-2) in spine sur- 
gery. Spine J 2014;14:552-9.

80. Phillips FM, Geisler FH, Gilder KM, Reah C, Howell KM, McAfee PC. Long-term Outcomes of the US FDA IDE Prospective, Randomized Controlled Clinical Trial Comparing PCM Cervical Disc Arthroplasty With Anterior Cervical Discectomy and Fusion. Spine (Phila Pa 1976) 2015;40:674-83.

81. Alvin MD, Abbott EE, Lubelski D, et al. Cervical arthroplasty: a critical review of the literature. Spine J 2014;14:2231-45.

82. Currier BL. Neurological complications of cervical spine surgery: C5 palsy and intraoperative monitoring. Spine (Phila Pa 1976) 2012;37:E328-34.

83. Hojo Y, Ito M, Abumi K, et al. A late neurological complication following posterior correction surgery of severe cervical kyphosis. Eur Spine J 2011;20:890-8.

84. Geck MJ, Macagno A, Ponte A, Shufflebarger HL. The Ponte procedure: posterior only treatment of Scheuermann's kyphosis using segmental posterior shortening and pedicle screw instrumentation. J Spinal Disord Tech 2007;20:586-93.

85. Harms J, Melcher RP. Posterior C1-C2 fusion with polyaxial screw and rod fixation. Spine (Phila $\mathrm{Pa}$ 1976) 2001;26:2467-71.

86. Ni B, Zhou F, Guo Q, Li S, Guo X, Xie N. Modified technique for C1-2 screw-rod fixation and fusion using autogenous bicortical iliac crest graft. Eur Spine J 2012;21:156-64.

87. Stulik J, Vyskocil T, Sebesta P, Kryl J. Atlantoaxial fixation using the polyaxial screw-rod system. Eur Spine J 2007;16:479-84.

88. Neo M, Fujibayashi S, Miyata M, Takemoto M, Nakamura T. Vertebral artery injury during cervical spine surgery: a survey of more than 5600 operations. Spine (Phila Pa 1976) 2008;33:779-85.

89. Wright NM, Lauryssen C. Vertebral artery injury in C1-2 transarticular screw fixation: results of a survey of the AANS/CNS section on disorders of the spine and peripheral nerves. American Association of Neurological Surgeons/Congress of Neurological Surgeons. J Neurosurg 1998;88:634-40.

90. Neo M, Sakamoto T, Fujibayashi S, Nakamura T. The clinical risk of vertebral artery injury from cervical pedicle screws inserted in degenerative vertebrae. Spine (Phila Pa 1976) 2005;30:2800-5.

91. Ludwig SC, Kramer DL, Balderston RA, Vaccaro AR, Foley KF, Albert TJ. Placement of pedicle screws in the human cadaveric cervical spine: comparative accuracy of three techniques. Spine (Phila Pa 1976) 2000;25:1655-67.

92. Richter M, Mattes T, Cakir B. Computer-assisted posterior instrumentation of the cervical and cervico-thoracic spine. Eur Spine J 2004;13:50-9.

93. Katonis P, Papadakis SA, Galanakos S, et al. Lateral mass screw complications: analysis of 1662 screws. J Spinal Disord Tech 2011;24:415-20.

94. Abumi K, Takada T, Shono Y, Kaneda K, Fujiya M. Posterior occipitocervical reconstruction using cervical pedicle screws and plate-rod systems. Spine (Phila Pa 1976) 1999;24:1425-34.

95. Fehlings MG, Errico T, Cooper P, Benjamin V, DiBartolo T. Occipitocervical fusion with a fivemillimeter malleable rod and segmental fixation. Neurosurgery 1993;32:198-207.

96. Vender JR, Rekito AJ, Harrison SJ, McDonnell DE. The evolution of posterior cervical and occipitocervical fusion and instrumentation. Neurosurg Focus 2004;16:E9.

97. Deutsch H, Haid RW Jr, Rodts GE Jr, Mummaneni PV. Occipitocervical fixation: long-term results. Spine (Phila Pa 1976) 2005;30:530-5.

98. Uematsu Y, Tokuhashi Y, Matsuzaki H. Radiculopathy after laminoplasty of the cervical spine. Spine (Phila Pa 1976) 1998;23:2057-62.

99. Satomi K, Nishu Y, Kohno T, Hirabayashi K. Longterm follow-up studies of open-door expansive laminoplasty for cervical stenotic myelopathy. Spine (Phila Pa 1976) 1994;19:507-10.

100. Gu Y, Cao P, Gao R, et al. Incidence and risk factors of C5 palsy following posterior cervical decompression: a systematic review. PLoS One 2014;9:e101933.

101. Mochida J, Nomura T, Chiba M, Nishimura K, Toh E. Modified expansive open-door laminoplasty in cervical myelopathy. J Spinal Disord 1999;12:38691.

102. Lee DH, Park SA, Kim NH, et al. Laminar closure after classic Hirabayashi open-door laminoplasty. Spine (Phila Pa 1976) 2011;36:E1634-40.

103. Kaptain GJ, Simmons NE, Replogle RE, Pobereskin L. Incidence and outcome of kyphotic deformity following laminectomy for cervical spondylotic myelopathy. J Neurosurg 2000;93:199-204.

104. Ikuta K, Tono O, Tanaka T, et al. Surgical complications of microendoscopic procedures for lumbar 
spinal stenosis. Minim Invasive Neurosurg 2007; 50:145-9.

105. Parikh K, Tomasino A, Knopman J, Boockvar J, Hartl R. Operative results and learning curve: microscope-assisted tubular microsurgery for 1 - and 2-level discectomies and laminectomies. Neurosurg Focus 2008;25:E14.

106. Podichetty VK, Spears J, Isaacs RE, Booher J, Bis- cup RS. Complications associated with minimally invasive decompression for lumbar spinal stenosis. J Spinal Disord Tech 2006;19:161-6.

107. Wu X, Zhuang S, Mao Z, Chen H. Microendoscopic discectomy for lumbar disc herniation: surgical technique and outcome in 873 consecutive cases. Spine (Phila Pa 1976) 2006;31:2689-94. 